\title{
Predicting the mechanical behaviour of carbon fibre reinforced silicon carbide with interlaminar manufacturing defects
}

\author{
Severin Hofmann ${ }^{\mathrm{a}}$ and Dietmar Koch \\ DLR, German Aerospace Centre, Institute of Structures and Design, Stuttgart, Germany
}

\begin{abstract}
A finite element approach based on experimental material data is presented in order to compute the mechanical reliability of carbon fibre reinforced silicon carbide, C/C$\mathrm{SiC}$, taking interlaminar manufacturing defects into account. The approach is evaluated on sample scale by modelling the flexural behaviour of $\mathrm{C} / \mathrm{C}-\mathrm{SiC}$ samples containing delaminations after liquid silicon infiltration (LSI) processing. The non-destructive evaluation methods, determination of fracture mechanical input data and the numerical cohesive zone approach are described. The numerical predictions of flexural stiffness and strength of samples with and without interlaminar defects were validated by bending tests of the respective samples. The difference between tensile and bending behaviour is explained by FE modelling for this group of CMC materials.
\end{abstract}

\section{Introduction}

Delaminations are the most common interlaminar defects observed in carbon fibre reinforced silicon carbide, C/C-SiC, produced by liquid silicon infiltration (LSI) process. In curved structures, the strong matrix shrinkage in contrast to the stable fibres always produces the risk of delamination due to differences in out-of plane and in-plane shrinkage during pyrolysis of the polymer green body.

The risk of delamination may be minimized by smart fibre alignment [1]. However, the risk increases with the complexity of the curved structure and for small scale series production where lay-up and processing may not be optimized to the very end due to cost issues.

The goal of the present work is to demonstrate a modelling approach which enables the prediction of the mechanical behaviour of $\mathrm{C} / \mathrm{C}-\mathrm{SiC}$ material which contains delaminations after processing. An experimentally validated $\mathrm{FE}$ approach, based on existing constitutive formulations, is presented. The bending test is used as a simple test case for the modelling approach. The non-linear, pseudo-plastic stress-strain behaviour is modelled by an anisotropic yield criterion. The two concurrent failure modes under flexural load, translaminar tensile failure and interlaminar shear failure, are modelled by cohesive zone formulations. The difference between tensile and bending strength is explained for this group of carbon fibre reinforced silicon carbide materials by considering the relevant material behaviour in the

\footnotetext{
${ }^{a}$ Corresponding author: Severin.Hofmann@dlr.de
}

This is an Open Access article distributed under the terms of the Creative Commons Attribution License 4.0, which permits unrestricted use, distribution, and reproduction in any medium, provided the original work is properly cited. 
(a)
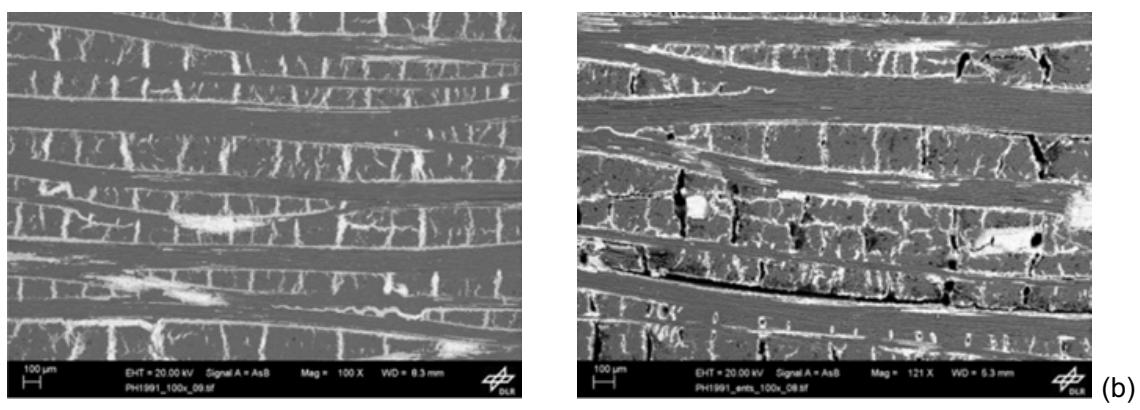

Figure 1. SEM images of microstructures from C/C-SiC in siliconized (a) and desiliconized state (b).

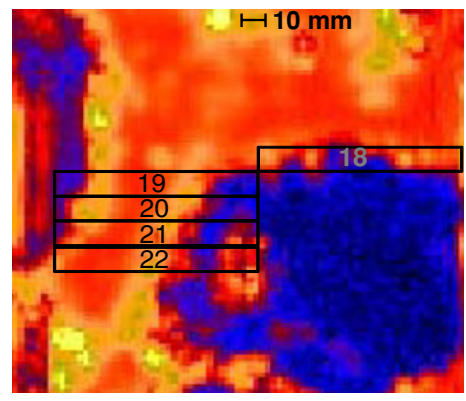

Figure 2. Ultrasound attenuation from partly delaminated C/C-SiC plate in desiliconized state (dark = high attenuation, light colour $=$ low attenuation); bending samples are marked with numbering.

finite element model. This paper is an up-date on two earlier publications of the authors. More details about the experimental and numerical approach may be found in $[2,3]$.

\section{Experimental set-up}

\subsection{Investigated material}

The investigated carbon fibre reinforced silicon carbide material, $\mathrm{C} / \mathrm{C}-\mathrm{SiC}$, was produced from HTA carbon fibre fabrics of twill style 2/2 in-house at the German Aerospace Centre by LSI-processing. The microstructure of $\mathrm{C} / \mathrm{C}-\mathrm{SiC}$ is built up by a dense $\mathrm{SiC}$ matrix, surrounding blocks of $\mathrm{C} / \mathrm{C}$-fibre bundles which contain carbon fibres and residual pyrolytic carbon, see Fig. 1(a) and (b). Further details on processing and microstructure can be found at Heidenreich [4]. The presented modelling approach is applicable on siliconized and desiliconized state of the material, see Fig. 1(a) and (b). The modelling with delaminations will focus on desiliconized material only, since for that state delaminations have to be considered most critical. Delaminations are usually formed during pyrolysis, than closed during siliconization and finally re-opened during desiliconization step when residual free silicon is removed by the application of carbon granulate on the CMC surface. That is why delaminations have to be considered for the structural integrity mainly in desiliconized state, e.g. for hot structures in re-entry applications [5].

Figure 2 shows the ultrasound attenuation from a delaminated C/C-SiC plate in desiliconized state. The bending samples taken for the evaluation of the modelling approach with defects are marked with numbers. The dark colour corresponds to highest ultrasound attenuation which corresponds to delaminated regions. The intention was to take partly delaminated samples from the boundary of delaminations in order to evaluate the crack propagation models. Further samples with and without 


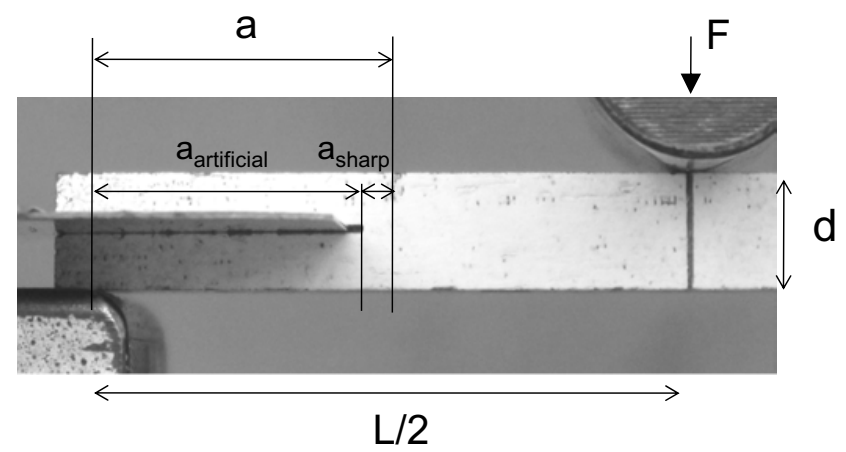

Figure 3. Pre-cracked part of set-up for ENF test with L/d-ratio 10 and initial crack length a; the total crack length $\mathrm{a}$ is the sum of cut-off grinded and pre-cracked part.

defects were taken from this plate, but samples 18-22 were selected for the model evaluation because they showed a high variety in extent and location of defects.

\subsection{Mechanical test set-up: Tensile, bending, SENB, ENF tests for standard material and bending tests of delaminated samples}

All mechanical tests were performed at room temperature at an universal testing machine from Zwick Inc. Tensile and bending tests were performed in $0 / 90^{\circ}, 15 / 75^{\circ}, 30 / 60^{\circ}$ and $+/-45^{\circ}$ direction relative to the fibre reinforcement. The bending test followed DIN EN 685-3 2002. Single edge notched bending (SENB) tests were performed in $0 / 90^{\circ}$ and $+/-45^{\circ}$ direction relative to the fibres with translaminar and in-plane crack propagation. The End-notched Flexure (ENF) test was performed similar as described in AITM standard [6], see Fig. 3. The ENF tests and bending tests with delaminations were performed in $0 / 90^{\circ}$ load direction for desiliconized material only. The span width/thickness-ratio (L/d) for ENF tests and for the validation tests was set to 10 in order to increase shear stresses relative to bending stresses. In that way, the probability for shear failure mode was increased. The samples were sprayed white before testing in order to facilitate detection of failure location and failure mode. An aluminium sheet of $0.3 \mathrm{~mm}$ thickness was inserted in the artificial, cut-off grinded pre-crack in order to prevent additional bending of the lower cantilever beam and to reduce friction, see Fig. 2 left side. The sharp pre-crack was produced by opening the grinded part with a scalpel.

\subsection{Non-destructive test set-up: $\mu$-computer tomography}

A $\mu$-computer tomograph, vtomex240, from Phoenix/GE Inc. was used to investigate the delaminations within the bending samples. The five samples, shown in Fig. 2, were scanned at once at a voxel size of $36 \mu \mathrm{m}$. The grey scale segmentation and determination of delamination size and position was done using the commercial code Mimics from Materialise Inc.

\section{Experimental results}

\subsection{Results from mechanical testing}

\subsubsection{Results from tensile and bending test}

Figure 4(a) shows the stress-strain curves in varying orientations relative to the fibre reinforcement evaluated from tensile and bending tests with strain gauge measurement. The bending failure stress and 

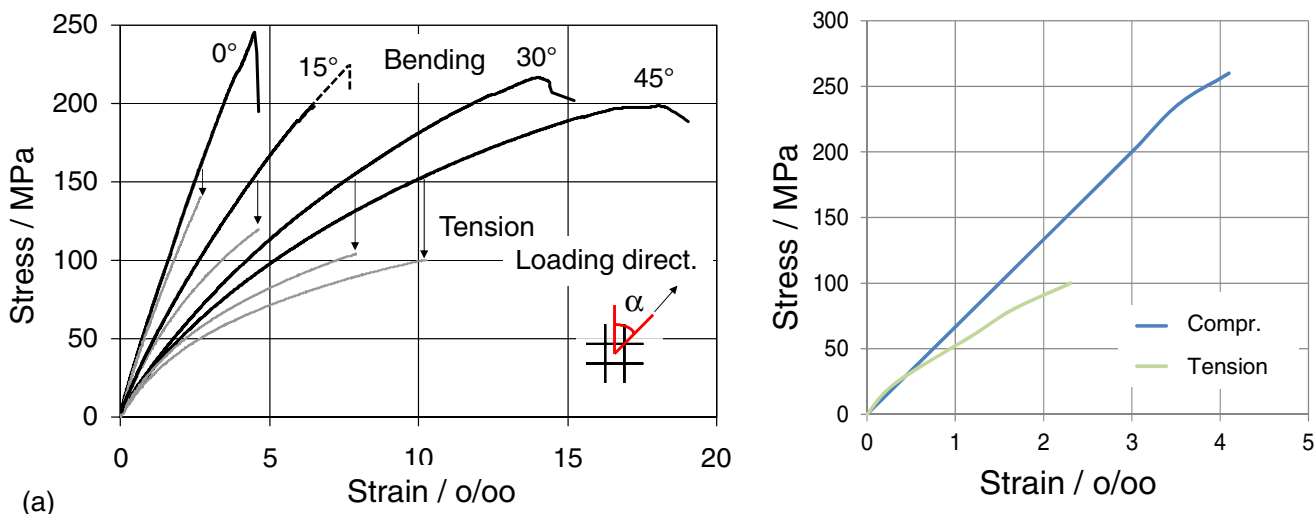

(b)

Figure 4. Stress-strain results from tensile and bending tests in varying orientations relative to the fibre reinforcement. Theoretical bending stresses were computed by beam theory; strain results were measured by strain gauges (a). Tensile and compression test results from Fink [7] (b).
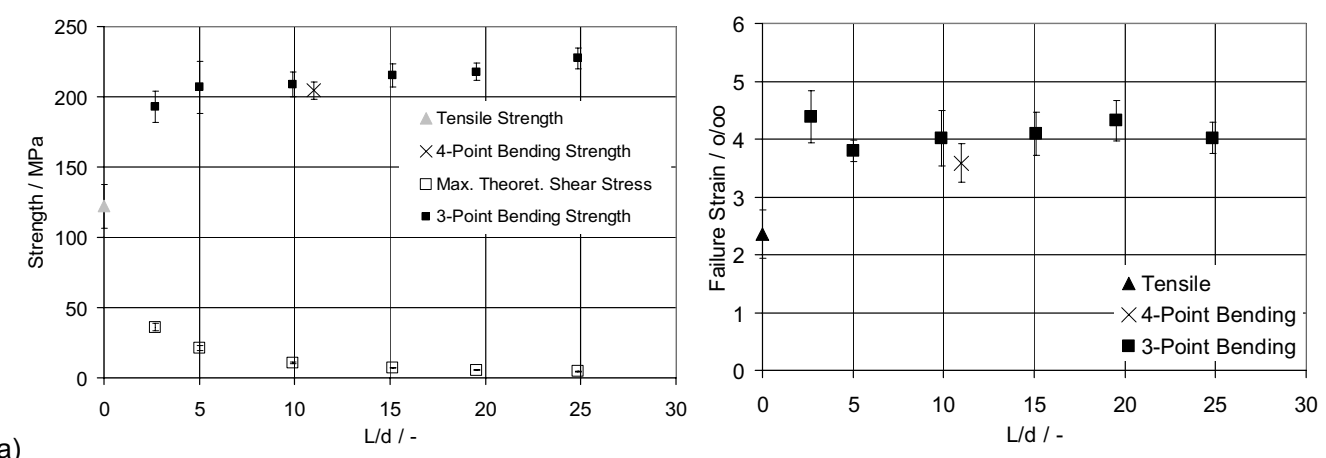

(b)

Figure 5. Maximum bending stresses from beam theory and corresponding shear stresses (a); failure strains from strain gauge measurement (b).

strain is exceeding the tensile curves by far. The off-set of bending curves shows that the computed stresses by beam theory do not correspond to true tensile stresses. At the same strain level, same stress has to be fulfilled. This fact shows that there is a deviation from beam theory which is most likely explained by differing compression and tensile stress-strain behaviour. This was already shown by the earlier work of Fink [7], compare Fig. 4(b): the linear-elastic compression behaviour supports the non-linear tensile side and leads to decreased effective tensile stresses relative to beam theory. The neutral plane is shifted upwards in direction of the central load introduction. The difference in failure strain, however, can not be explained by the differing tensile and compression behaviour. A different explanation had to be found. Fink [7] suggested a consideration of fracture toughness. For $\mathrm{SiC}$ fibre reinforced composites an explanation by statistical fibre strength and Weibull-like volume effects is most common [8, 9]. In order to prove if volume effects exist in C/C-SiC-material, 4-point and 3-point bending tests at varying length/thickness (L/d)-ratios were performed, see results in Fig. 5(a) and (b). The difference between 3-point and 4-point bending strength and failure strain is negligible. Larger (L/d)-ratios do not decrease but increase strength. Thus higher strength is observed at larger loaded volumes. This is caused by shear effects which decrease the theoretical bending strength at low L/dratios. The failure strain from strain gauges is almost constant at varying L/d-ratios although the sample 

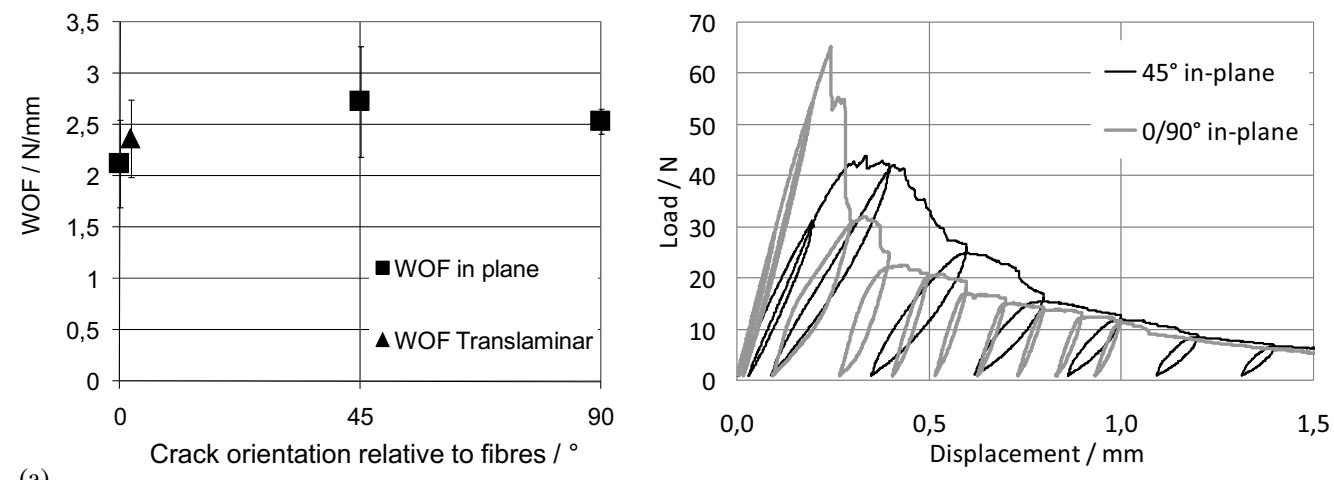

(a)

Figure 6. WOF determined from area under load-displacment curves from SENB tests (a), load-displacementcurves with un/reloadig-cycles from $\mathrm{a} / \mathrm{b}=0.4(\mathrm{~b})$.

volume was increasing with L/d-ratio. That is why a volume effect is excluded for this group of carbon fibre reinforced materials. Shear failure was not observed for any L/d-ratio, proving the high interlaminar shear strength ( $>25 \mathrm{MPa}$ ) of $\mathrm{C} / \mathrm{C}-\mathrm{SiC}$ standard material without interlaminar manufacturing defects.

\subsubsection{Results from SENB test}

Since volume effects are not applicable to $\mathrm{C} / \mathrm{C}-\mathrm{SiC}$ for explaining the difference in failure strains from bending and tensile test, see Sect. 3.1.1, the fracture toughness of $\mathrm{C} / \mathrm{C}-\mathrm{SiC}$ was analysed in detail [7]. The work of fracture (WOF) was determined for siliconized and desiliconized C/C-SiC. Different crack orientations relative to the fibre reinforcement showed similar WOFs, see Fig. 6(a) and (b). The WOF was determined as defined by Nakayama [10]. The translaminar and in-plane WOF is comparable also.

\subsubsection{Results from ENF test}

Two failure modes are usually observed for $\mathrm{C} / \mathrm{C}-\mathrm{SiC}$ with delaminations under bending load: inplane tensile and interlaminar shear failure. Compression failure was not expected because the ratio of compression to tensile strength is $>2$. Interlaminar failure had to be desribed additionally to translaminar crack propagation, see Sect. 3.1.2. In order to do so, ENF tests were performed and evaluated in order to determine the critical energy release rate $\mathrm{G}_{\text {IIc }}$ under mode II loading. In average a $\mathrm{G}_{\text {IIc }}$ of $0.32+/-0.05 \mathrm{~N} / \mathrm{mm}$ was determined by the equations from Szekrenies [11] for six valid samples:

$$
G_{I I c}=\frac{9 a^{2} F u}{2 b\left(3 a^{3}+\left(\frac{L^{3}}{4}\right)\right)} .
$$

With a: initial crack length; F: load at crack onset; L: span width; u: displacement; b: width.

The average $\mathrm{G}_{\text {IIc }}$ value of $0.32 \mathrm{~N} / \mathrm{mm}$, the average Young's Modulus of $43.4 \mathrm{GPa}$ computed from the stiffness of varying initial crack lengths and an average height of $4.94 \mathrm{~mm}$ was used to calculate the crack propagation curve in Fig. 7. The following equation from Allix et al. [12] was used:

$$
u=\frac{F L^{3}}{384 E I}+\frac{16}{F^{2}}\left(\frac{b G_{I I c}}{3}\right)^{3 / 2} \sqrt{E I},
$$

With E: Young's Modulus and I: geometrical moment of inertia of one half-beam, i.e. $\mathrm{I}=$ $b^{*}(\mathrm{~d} / 2)^{3 / 12}$; b: width; d: height. 


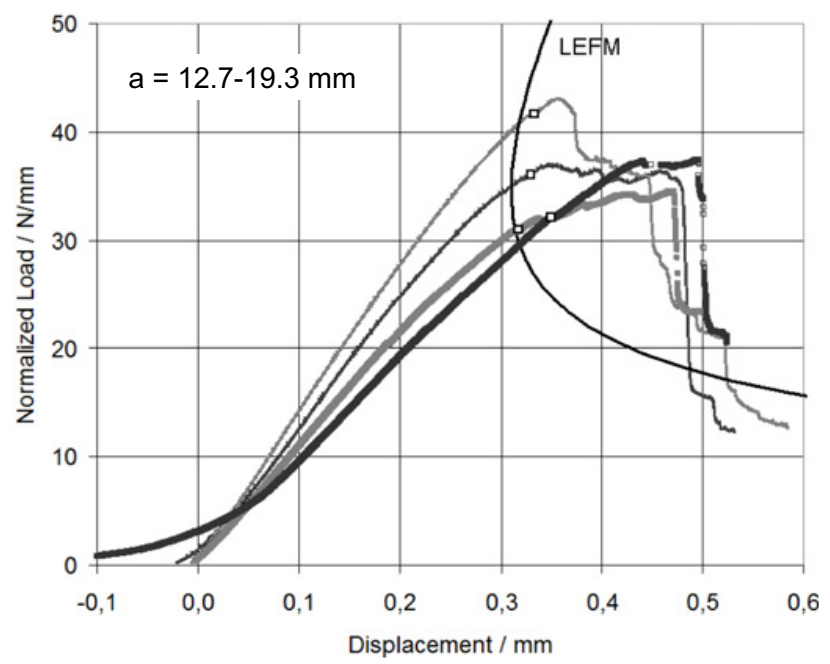

Figure 7. Width-normalized load-displacement curves from ENF tests with different initial crack lengths a; critical load points and the crack propagation curve from $\mathrm{LEFM}$ for $\mathrm{E}=43.4 \mathrm{GPa}$ and an average $\mathrm{G}_{\mathrm{IIc}}$ are indicated.

Since visual crack observation was not possible, especially for the initiation load, the first clear kinking of the load-displacement curve was used as critical load point for crack onset. A good correlation of the crack propagation curve, Eq. (2), from Linear Elastic Fracture Mechanics, LEFM, with experimental delamination onset loads is demonstrated at various initial crack lengths in Fig. 7.

\subsubsection{Results from bending tests on partly delaminated $\mathrm{C} / \mathrm{C}$-SiC}

Bending tests with L/d-ratio of 10 were performed in order to evaluate the fracture mechanical modelling approach. The samples from the delaminated plate, see Fig. 2, were taken by cut-off grinding. As expected, the area, number and location of delaminations had a significant impact on the sample's stiffness and maximum load carrying capability. Only one sample (18), with small extent of delamination, reached the standard bending strength of desiliconized $0 / 90^{\circ}-\mathrm{C} / \mathrm{C}-\mathrm{SiC}$ of about $160 \mathrm{MPa}$, see Fig. 8(a) and (b).

\section{Numerical set-up}

All FE simulations were performed using the commercial code ANSYS Workbench 12.1 [13]. Available material models within ANSYS were used and adapted. 3D models were used for computing tensile and bending behaviour in various loading orientations (including off-axis). 2D models were applied for the computation of ENF samples and for delaminated samples $\left(0 / 90^{\circ}\right.$ only).

\subsection{Non-linear model for tensile and bending load}

First, the non-linear tensile behaviour was mapped with help of an anisotropic yield model. The nonlinear model is based on a generalized Hill yield criterion from Shih and Lee $[14,15]$ in combination with a bi-linear isotropic hardening by Valliappan et al. [16]. Since C/C-SiC does not show a clear yield point, like it is typical for metallic materials, the yield stresses $\sigma_{y}$ and $\tau_{y}$ were set as half of the strength values. The Young's moduli and tangent moduli were determined as corresponding secant slopes. Further details may be found in the ANSYS documentation [13] and in [3]. 

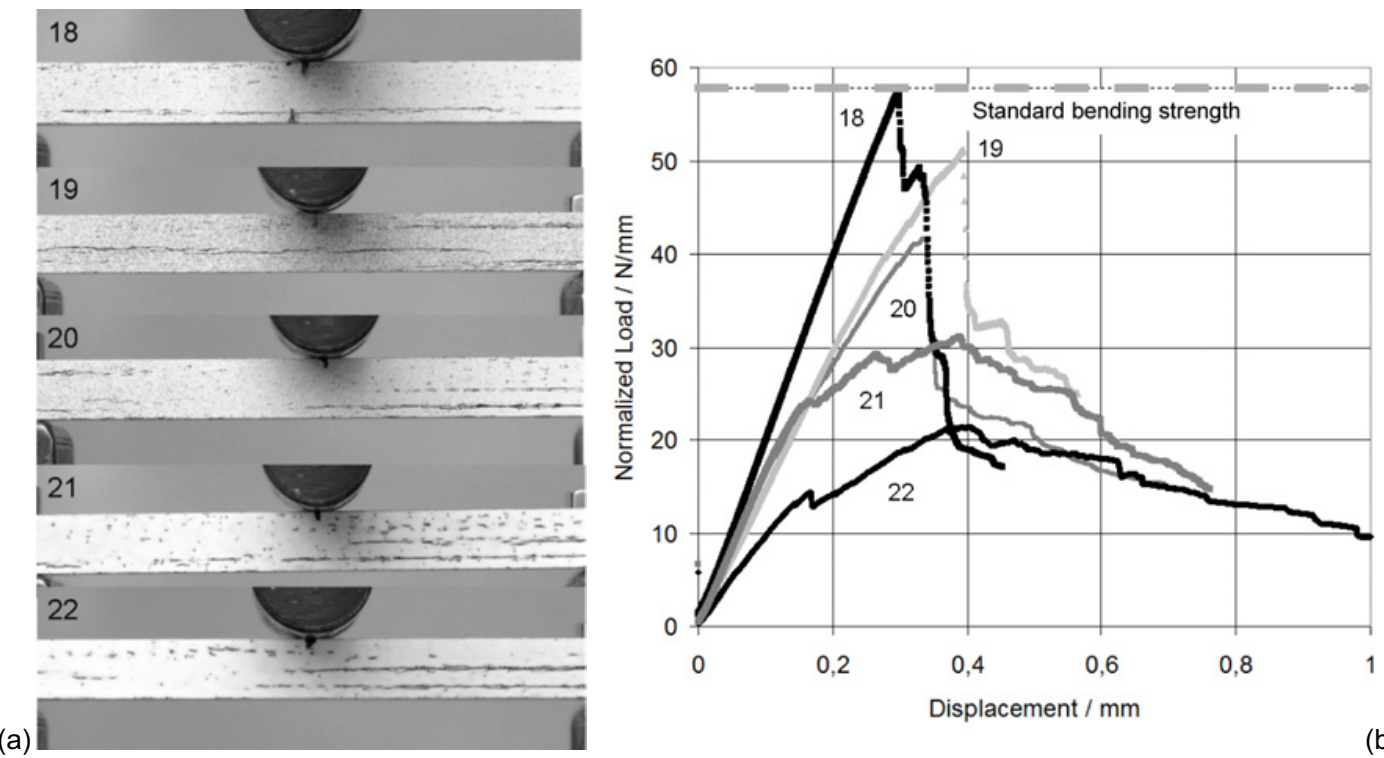

(b)

Figure 8. White sprayed bending samples from delaminated plate before testing (a); load-displacement curves of the respective samples (b).

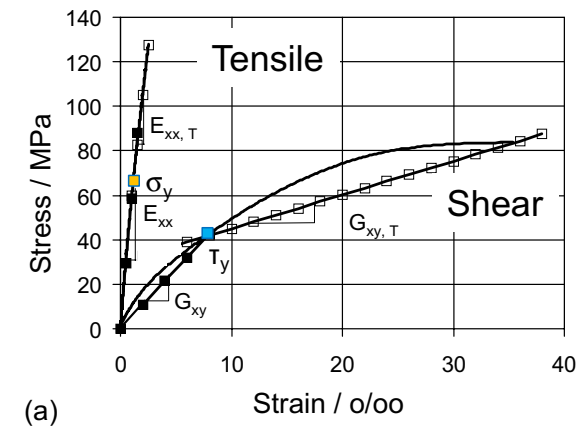

\begin{tabular}{|c|c|c|c|}
\hline & $\mathrm{E} / \mathrm{GPa}$ & $\begin{array}{c}\text { E } \\
\mathrm{E}_{\mathrm{T}} / \\
\mathrm{GPa}\end{array}$ & $\begin{array}{c}\text { Yield } \\
\text { stress: } \sigma_{\mathrm{y}}, \\
\mathrm{T}_{\mathrm{y}} / \mathrm{MPa}\end{array}$ \\
\hline$\sigma_{\mathrm{xx}}$ & 58 & 44 & 64 \\
\hline$\sigma_{\mathrm{yy}}$ & 58 & 44 & 64 \\
\hline & & 1.6 & 40 \\
\hline
\end{tabular}

(b)

Figure 9. Determination of in-plane input data for $0 / 90^{\circ}-\mathrm{C} / \mathrm{C}-\mathrm{SiC}$ for yield model (a), the yield stresses, Young's moduli and tangent moduli are summarized in (b).

The anisotropic yield model was first used to model the non-linear tensile behaviour in various loading directions relative to the fibre reinforcement. Then, it was used together with an orthotropic elastic model in order to model the SENB and bending test. The compression side was modelled linearelastic, the tensile side was modelled with the mentioned yield model, see Fig. 10. The set-up for SENB modelling was similar but with $\mathrm{L} / \mathrm{d}=4$ and a pre-crack in the middle followed by cohesive zone elements. More details about the SENB model may be found in [3].

\subsection{Modelling of translaminar crack propagation}

A cohesive zone for modelling translaminar crack initiation and propagation, i.e. bending failure, was introduced in the middle of the sample where highest tensile stresses are occurring, see Fig. 10 and 


\section{MATEC Web of Conferences}

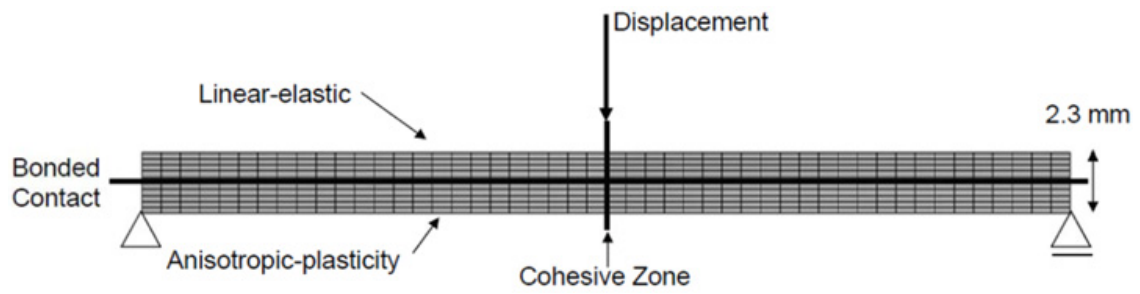

Figure 10. Set-up for modelling bending test.

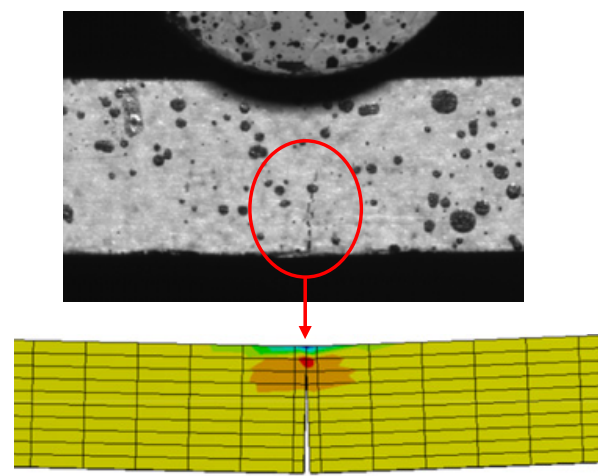

(a)

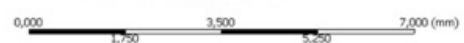

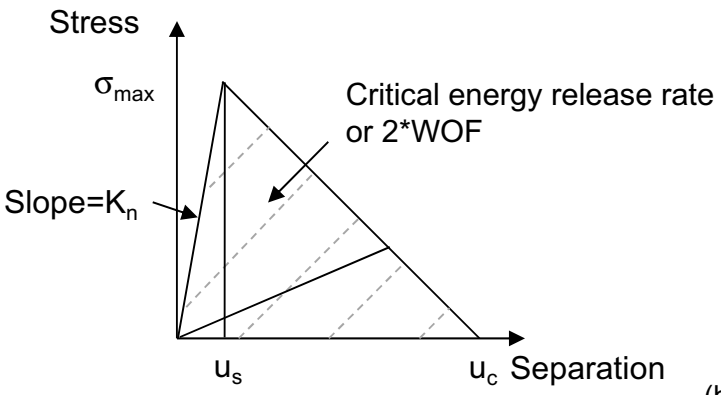

(b)

Figure 11. Modelling of bending failure by cohesive zone elements at the maximum tensile stress region (a), bilinear softening law used within ANSYS (b).

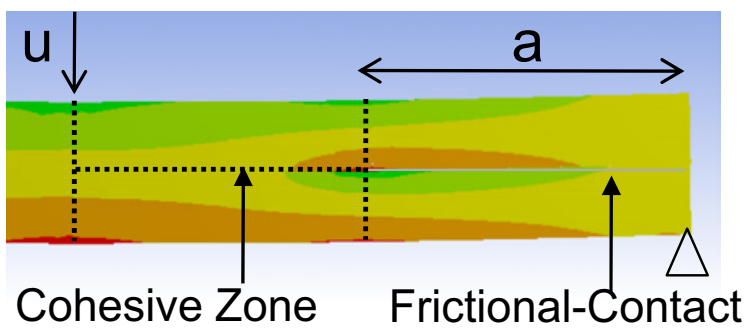

Figure 12. Pre-cracked part of ENF model with colour-coded longitudinal stress distribution; contact and cohesive zone regions (horizontal + vertical) are indicated.

Fig. 11(a). A linear softening rule, Fig. 11(b), was applied. The maximum stress value, or crack initiation value, was set as maximum tensile stress in the respective loading direction. The stiffness was set to $10 \mathrm{e} 6 \mathrm{MPa} / \mathrm{mm}$ which is considered ideal rigid behaviour. The critical energy release rate was set to two times the work of fracture, WOF, i.e. $2 * 2.5 \mathrm{~N} / \mathrm{mm}=5 \mathrm{~N} / \mathrm{mm}$, following the theory from Rice, Griffith, Dugdale, Barenblatt [17-20].

\subsection{Modelling of interlaminar crack propagation}

The interlaminar shear crack propagation was enabled by introducing cohesive zone elements horizontally at the regions of highest shear stresses. That is next to delaminated regions, see Fig. 12. 

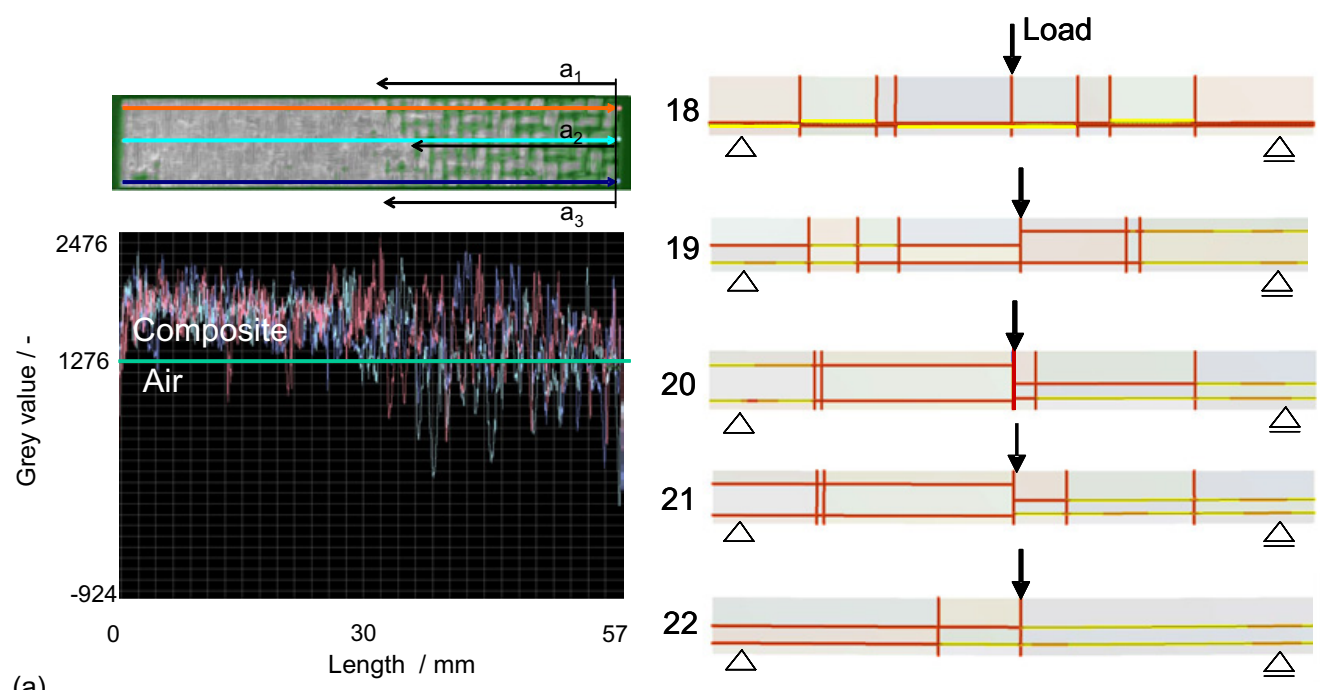

(b)

Figure 13. Exemplary determination of average delamination length from $\mu$-CT: virtual cut through delaminated area $($ green $=$ air) $(\mathrm{a}) ; 2 \mathrm{D}$ cohesive zone and contact models (yellow/orange $=$ frictional contact, red $=$ cohesive zone) (b).

The cohesive zone law as described in Fig. 11(b) was used again. The delaminated region itself was modelled as frictional contact. Details about the impact of the coefficient of friction, COF, may be found in [2]. Due to the inserted aluminium sheet during testing, see Fig. 3, the COF was set to 0 in this case. The maximum shear stress was set to $25 \mathrm{MPa}$ as measured from compression shear test [4]. The critical energy release rate $\mathrm{G}_{\text {IIc }}$ was set to $0.32 \mathrm{~N} / \mathrm{mm}$, as determined in Sect. 3.1.1. The ENF model, see Fig. 12, was enriched with perpendicular cohesive zones at the maximum tensile stress regions in order to enable translaminar tensile failure, too. The maximum longitudinal tensile stress regions are indicated with red colour in Fig. 12. The ENF test as well as the delaminated samples under bending load were simulated with linear-elastic properties only, since non-linear effects in $0 / 90^{\circ}$ direction are rather small, see Fig. 4(a) and Sect. 5.2.

\subsection{Modelling bending samples with delaminations from manufacturing}

Finally, the cohesive zone approach was transferred on the samples taken from the delaminated plate, shown in Fig. 2. A similar approach was used as described in Sect. 4.3 for the ENF test, the horizontal and vertical cohesive zones were applied at the respective maximum stress regions. That means horizontal and vertical cohesive zones were introduced at the end of each delamination plus one vertical cohesive zone in the middle of the sample (highest bending moment). In that way a high number of possible failure locations was enabled. The delamination itself was modelled as frictional contact with $\mathrm{COF}=0.7$, from [21]. The value was increased in contrast to ENF modelling since C/C-SiC surfaces are directly in contact in this case.

The average delamination length and position was determined by averaging three length measurements (green area, see Fig. 13(a)) using the commercial code Mimics by Materialise Inc. The average delamination length was used for the design of the 2D-FE-models, Fig. 13(b). The proof that a diagonal 3D delamination is comparable with the average 2D delamination length may be found in [2]. 


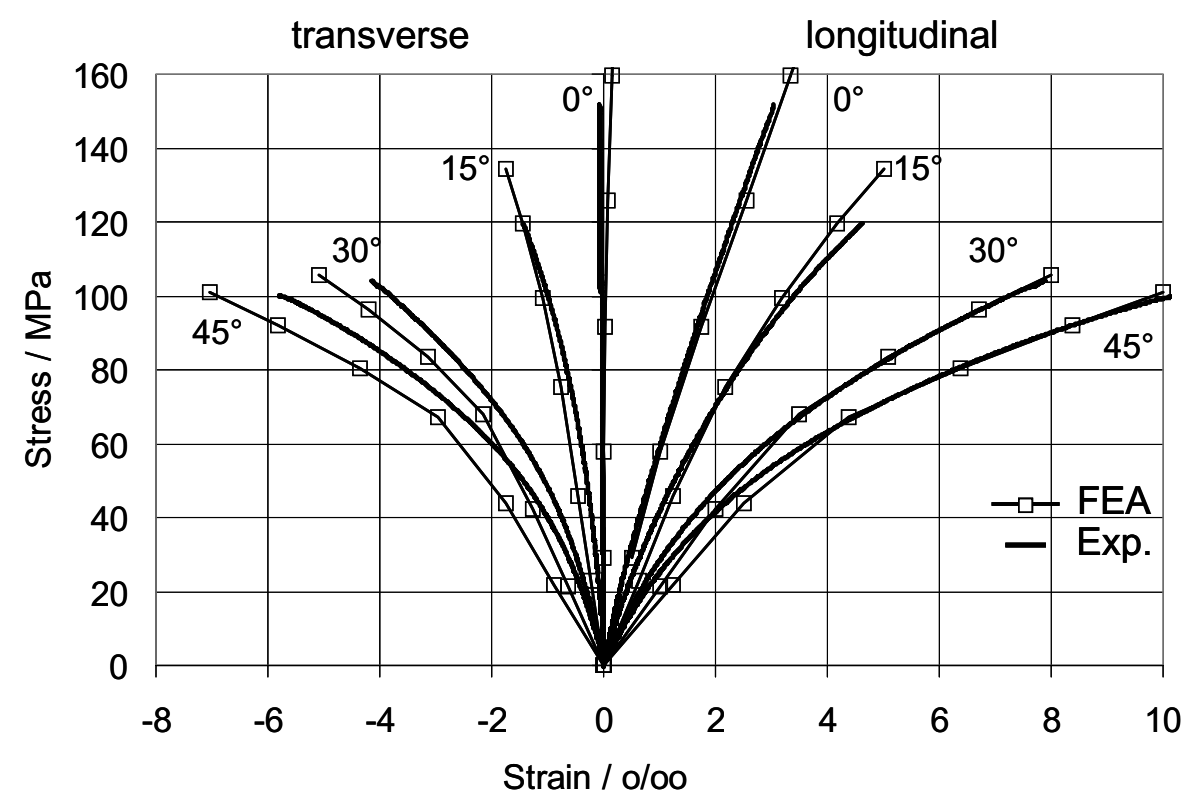

Figure 14. Experimental and numerical stress-strain curves for C/C-SiC under varying loading directions relative to the fibre reinforcement; longitudinal and corresponding transverse strains are plotted.

\section{Numerical results}

\subsection{Non-linear model under tensile load}

First, the isotropic hardening model presented in Sect. 4.1 was used to model the stress-strain behaviour of a simple $\mathrm{C} / \mathrm{C}-\mathrm{SiC}$ cube under tensile load. The material coordinate system was rotated in order to model varying load directions relative to the fibre reinforcement. The longitudinal and transverse stress-strain behaviour was evaluated from ANSYS. Figure 14 shows a relatively good agreement between experimental and numerical results. The initial stiffnesses are slightly underestimated by the non-linear model, which may be explained by the simple bilinear input. Since the behaviour was overall mapped quite well, it was then applied for the tensile side of the bending beam, see Sect. 5.2.

\subsection{Modelling of translaminar crack propagation and bending failure}

In order to proof the validity of the cohesive zone approach in combination with the non-linear tensile model, from Sect. 4.1, the translaminar SENB test was modelled with non-linear tensile side and cohesive zone in the centre to enable crack propagation starting from the central pre-crack. Figure 15(a) and (b) show a good agreement of load-deflection behaviour and failure stresses from FEA and SENB test. In $0 / 90^{\circ}$ direction the non-linear effects are rather small, that is why the theoretical bending strength of the plasticity model is only $20 \mathrm{MPa}$ above the linear-elastic model. Both models are incorporating the cohesive zone approach. More information about the SENB model may be found in $[2,3]$. The computations from LEFM in Fig. 15(a) and (b) were performed following the work from Tada et al. [22] with an average $\mathrm{K}_{I c}$ value of $5.4 \mathrm{MPam}^{1 / 2}$ and an experimental stiffness of $7033 \mathrm{~N} / \mathrm{mm}$ for $\mathrm{a} / \mathrm{d}=0$ at $\mathrm{L} / \mathrm{d}=4$ as determined from SENB test.

Further on the non-linear constitutive model from Sect. 4.1 and the cohesive zone approach were used to describe the bending behaviour without pre-cracks. Figure 15(a) shows the corresponding 

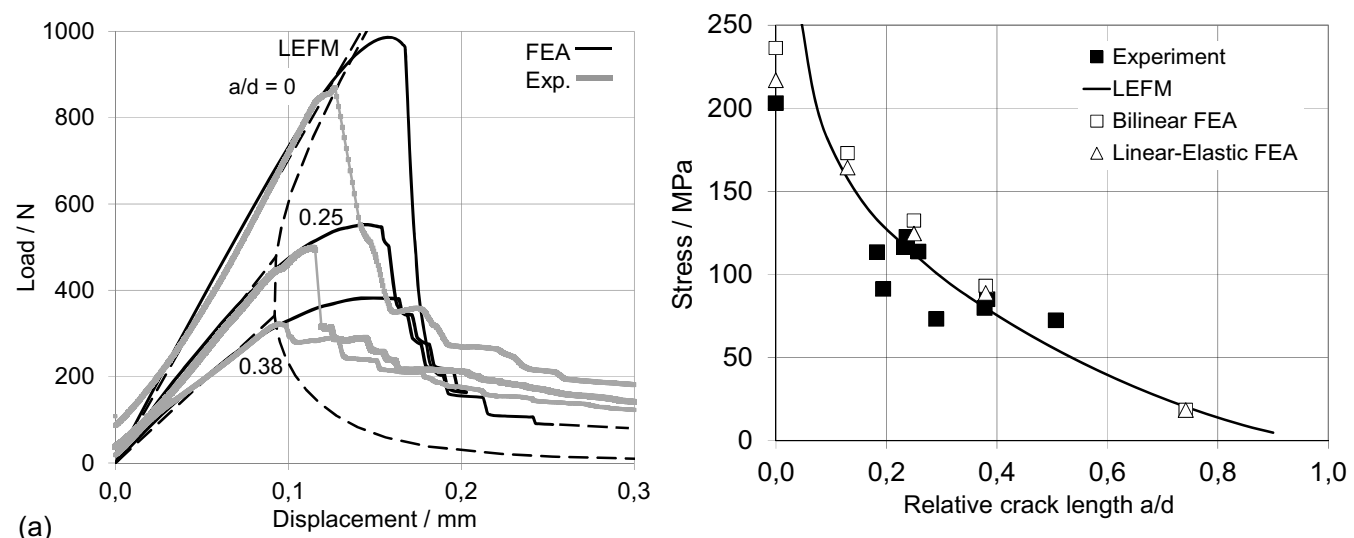

(b)

Figure 15. Comparison of cohesive zone modelling with experimental load-displacement curves from SENB test and computations from LEFM (a); comparison of theoretical bending strength from beam theory for SENB test, linear and non-linear FEA plus predictions from LEFM (b).

(a)
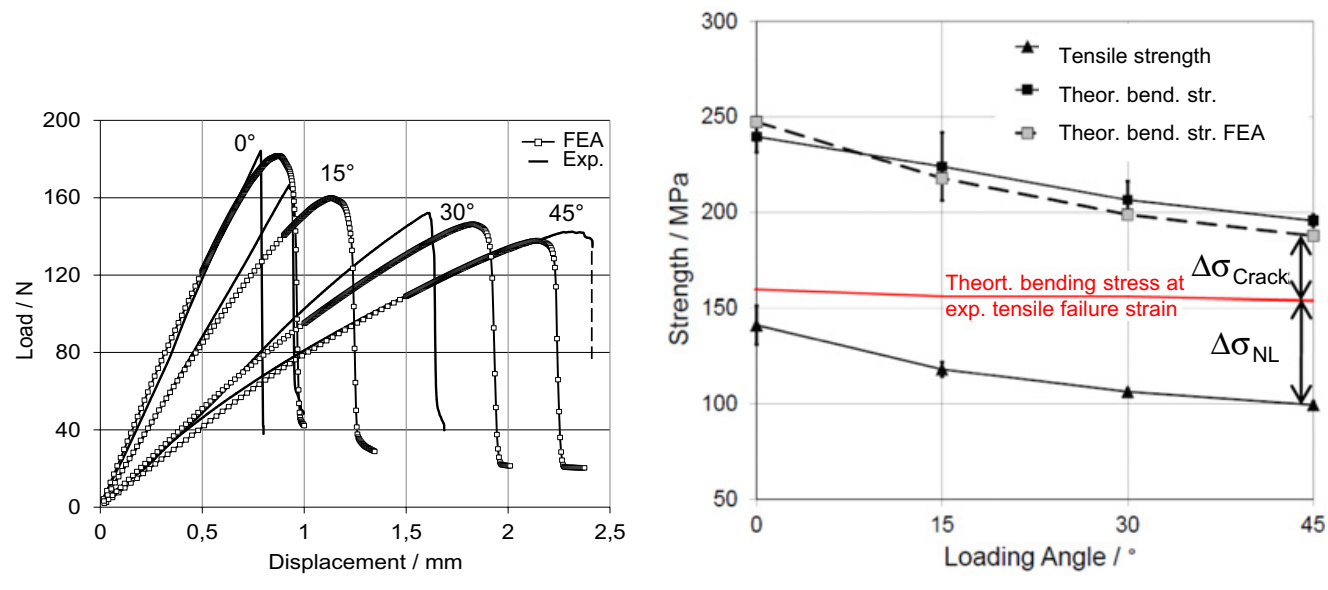

(b)

Figure 16. Comparison of load-deflection curves from bending test and the non-linear/cohesive zone FEA (a); explanation of theoretical bending strength computed by beam theory (b).

load deflection curves from FEA and bending test for $0 / 90^{\circ}, 15 / 75^{\circ} 30 / 60^{\circ}$ and $+/-45^{\circ}$ longitudinal orientation. A good agreement was reached. Figure 16(b) is explaining the effective theoretical bending strength which is resulting from beam theory.

Therefore the theoretical bending strength from beam theory for $\mathrm{C} / \mathrm{C}$-SiC may be explained directionally by the following equation:

$$
\sigma_{\text {Bending }}=\sigma_{\text {Tension }}+\Delta \sigma_{N L}+\Delta \sigma_{\text {Crack }} .
$$

That means: the theoretical bending strength from beam theory is the directional tensile strength plus a directional offset value $\Delta \sigma_{\mathrm{NL}}$ caused by differing compression and tensile stress-strain behaviour. This value is higher for off-axis orientations than for the almost linear-elastic on-axis orientation $0 / 90^{\circ}$. The red line in Fig. 16(b) was evaluated by comparing the theoretical bending stress at tensile failure strain in Fig. 4(a). This line indicates how much the true stress at the outer tensile surface is overestimated by beam theory. Finally, a directional offset caused by the fracture toughness of the material $\Delta \sigma_{\text {Crack }}$ 


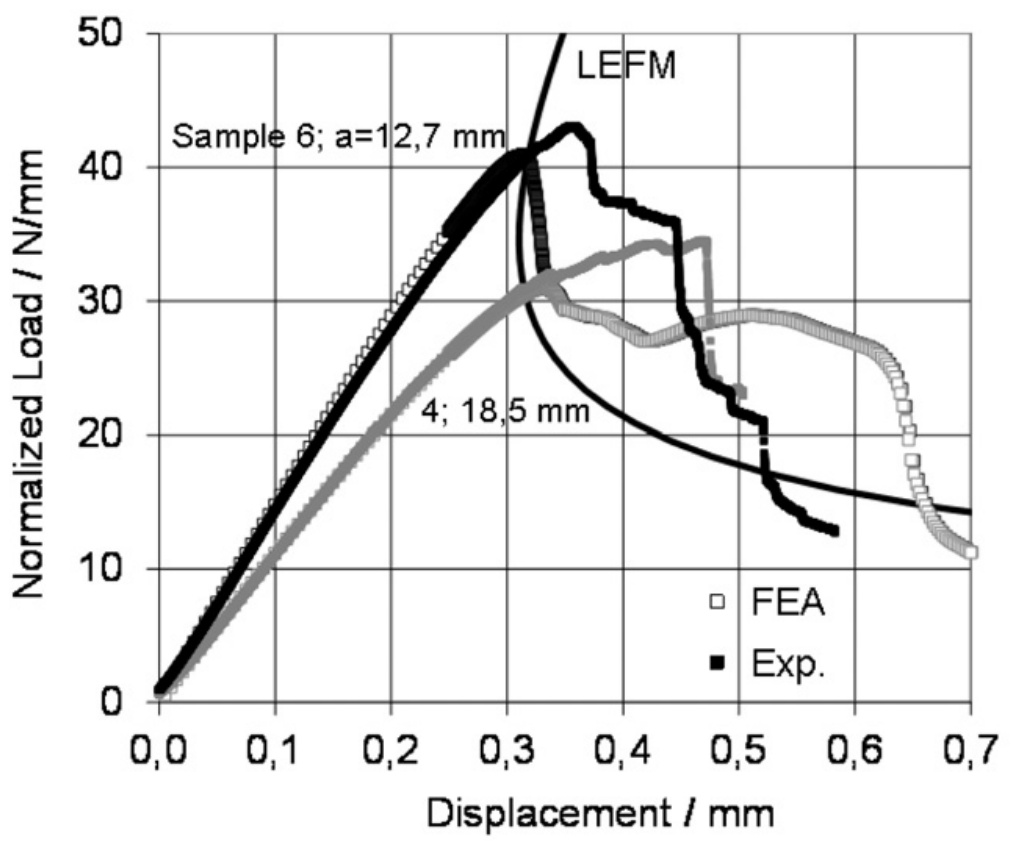

Figure 17. Width-normalized load-displacement curves from experiment and FEA for two different initial crack lengths a; sample labelling is indicated.

is added to Eq. (3), giving altogether the theoretical bending strength from beam theory. The WOF is constant for all orientations, see Sect. 3.1.2. Due to the varying stiffnesses the effective stress offset $\Delta \sigma_{\text {Crack }}$ is directional, however.

Crack initiation in $\mathrm{C} / \mathrm{C}-\mathrm{SiC}$ starts at the directional tensile failure strain, see Fig. 4(a), but the maximum bending load will be defined by the pre-crack starting to propagate which depends on the fracture toughness (WOF) of this material.

\subsection{Modelling of interlaminar crack propagation}

In Fig. 15(b) and Fig. 16(b) it was demonstrated that the effect of the non-linear tensile behaviour is only making a difference of about $20 \mathrm{MPa}$ relative to the beam theory for $0 / 90^{\circ}$ loading direction. That is why the non-linear material model was not used for the ENF simulations and for the simulations of bending samples with interlaminar manufacturing defects. Those tests were performed in $0 / 90^{\circ}$ direction only. Instead, the critical stress level for failure initiation was simply increased by $20 \mathrm{MPa}$ within linear-elastic models which corresponds to the stress decrease due to differing tensile and bending behaviour $\Delta \sigma_{\mathrm{NL}}$ relative to beam theory.

The next step was to prove that interlaminar shear crack propagation may also be modelled by the cohesive zone approach. For that reason the ENF tests described in Sect. 3.1.3 were modelled by finite elements. Horizontal cohesive zones were introduced at the locations of maximum interlaminar shear stresses, see Sect. 4.3.

Figure 17 shows that the crack onset is well reproduced by finite elements. First shear failure is observed and then bending failure. The only difference between FEA and experiment is the shear crack propagation length. In FEA the shear crack propagates up to the central load point; in experiment the crack propagation stops and bending failure is observed before the shear crack is reaching the central 


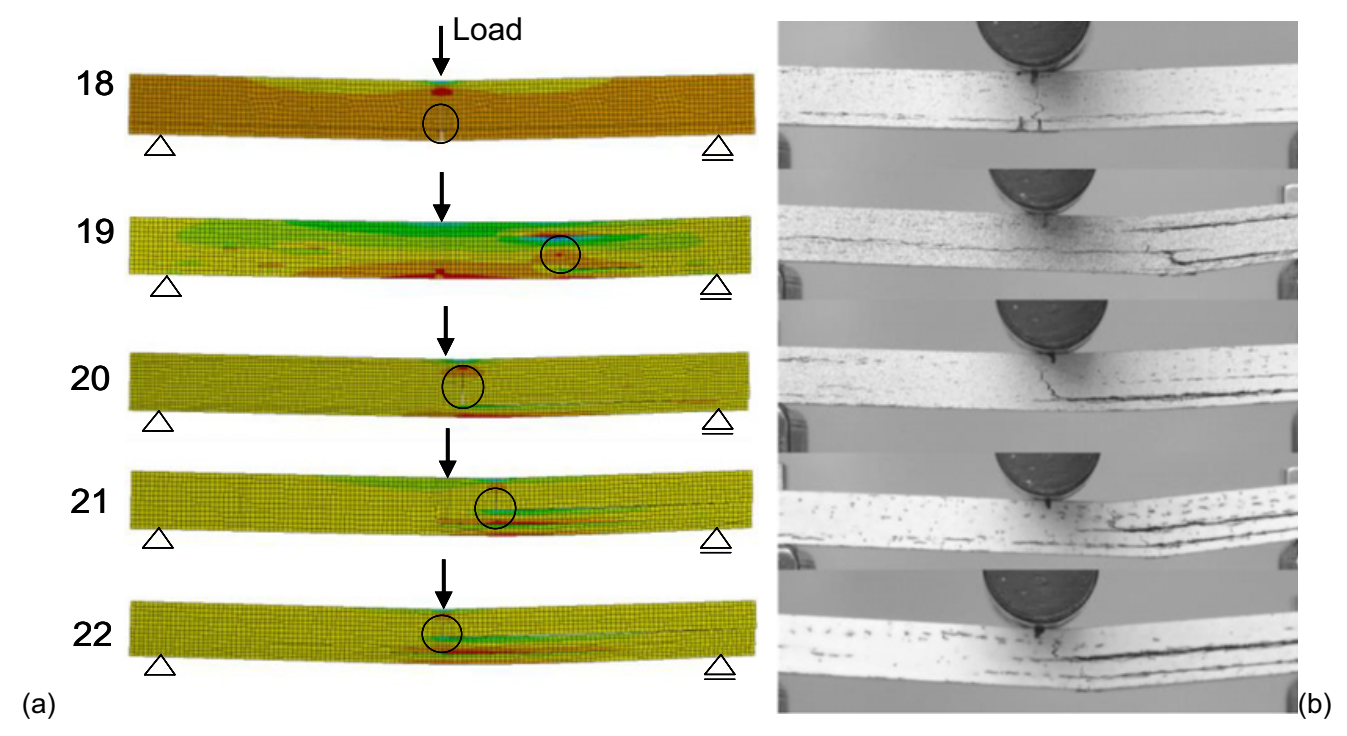

Figure 18. Longitudinal stress distribution in FEA after failure, the cohesive failure region is encircled (a), corresponding bending samples after failure (b).

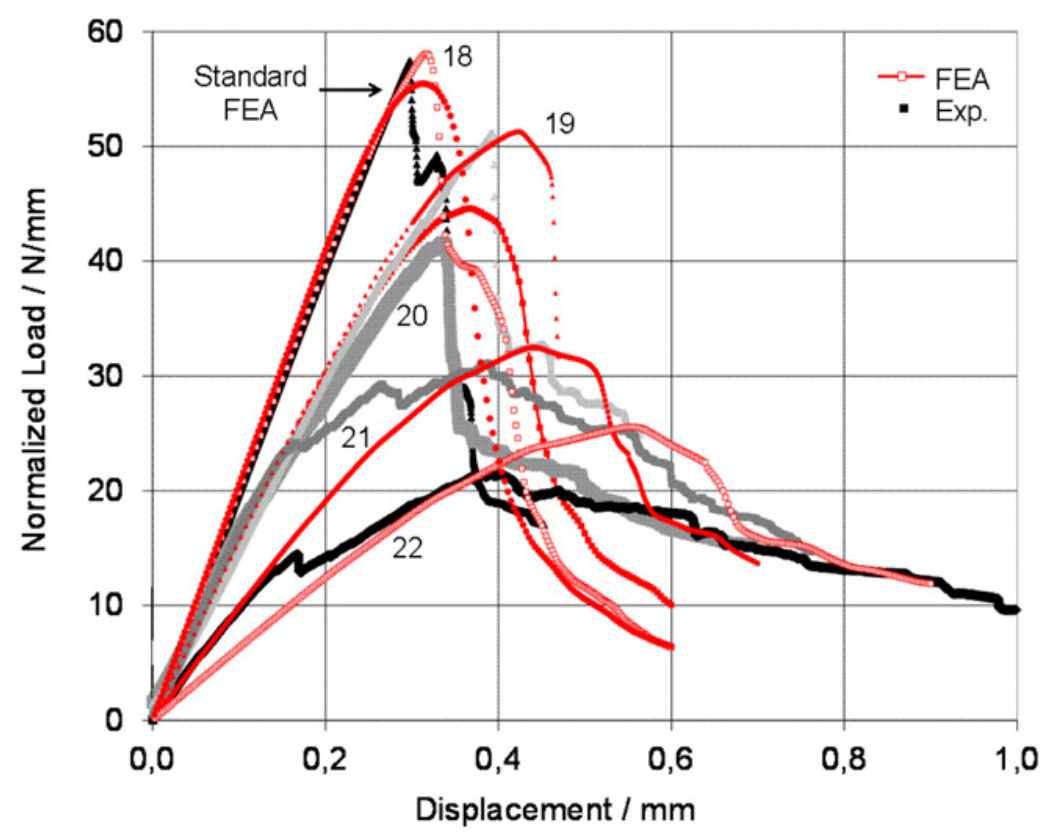

Figure 19. Comparison of load-displacement behaviour from FEA and bending test of partly delaminated samples; load-displacement curve from a standard FEA without defects is compared.

load line, i.e. at lower displacements, see Fig. 17. The bending failure in FEA occurred directly under the central load introduction. Bending failure was observed at the lower side in experiment too, but closer to the initial interlaminar crack front. 


\section{MATEC Web of Conferences}

\subsection{Modelling of bending samples with real delaminations}

The final evaluation of the presented FE approach was modelling the bending test of the samples 18-22 from the delaminated plate in Fig. 2. Figure 18(a) and (b) show that the failure location and failure modes from FEA and experiment do agree well. All samples failed due to translaminar tensile failure. Figure 19 shows that the FE approach was able to predict stiffness and maximum load of the five samples with true defects from manufacturing with good confidence. Sample 18 is additionally interesting because the FEA predicted that this sample, containing a little delamination at the lower central section, will show even a bit higher load carrying capacity than the standard FEA of the same geometry without defects. This fact shows that delaminations do not always need to have a negative impact on the mechanical performance. The same effect was observed in the bending test of sample 18: the delamination was hindering translaminar crack propagation, in that way a second load peak was created which caused an increase in overall fracture toughness. The average bending strength of desiliconized material without defects was also reached by sample 18. The other samples showed, as expected, a strong deterioration of stiffness and maximum load carrying capability due to delaminations.

\section{Summary}

An experimentally based step-by-step approach towards the FE modelling of ceramic matrix composites with interlaminar manufacturing defects was presented. Available material models were adapted and combined for modelling the fabric reinforced $\mathrm{C} / \mathrm{C}$-SiC material. The detailed information about location, size and number of delaminations was taken from $\mu$-computer tomography data.

The following material characteristics had to be considered in order to predict the behaviour with manufacturing defects under bending load:

- quantified difference in stress-strain behaviour under tensile and compression load,

- tensile strength and translaminar fracture toughness in order to describe bending failure,

- interlaminar shear strength and fracture toughness in order to describe delamination onset under mode II loading.

Good agreement of the FE modelling approach and the experimental behaviour was proven. Especially, the prediction of failure mode, location and failure initiation load was reliable. The initial stiffness was slightly underestimated in some cases. The reason for that were silicon carbide bridges which were initially connecting the delaminated surfaces and were not considered in the simplified, continuously delaminated areas within FE modelling. In the future work a transfer on 3D with a mixed mode delamination criterion in combination with residual-stress analysis is planned in order to evaluate curved structural parts, like re-entry components and satellite communication structures.

The authors wish to express their thanks for the persistent scientific support by Prof. Heinz Voggenreiter from DLR Stuttgart, Institute of Structures and Design, and Prof. Siegfried Schmauder from University Stuttgart, Institute for Materials Testing, Material Science and Strength of Materials.

\section{References}

[1] F. Breede, R. Jemmali, D. Koch, Design and testing of a C/C-SiC nozzle extension manufactured via filament winding technique and liquid silicon infiltration, $10^{\text {th }}$ PACRIM, June 2013, San Diego, USA

[2] S. Hofmann, Effect of interlaminar defects on the mechanical behaviour of fibre reinforced silicon carbide, Dissertation, University Stuttgart, 2013 
[3] S. Hofmann, B. Öztürk, D. Koch, H. Voggenreiter, Experimental and numerical evaluation of bending and tensile behaviour of carbon fibre reinforced SiC, Composites: Part A, 43 (2012), pp. $1877-1885$

[4] B. Heidenreich, Manufacturing of CMC by Liquid Silicon Infiltration (LSI), Wiley-VCH, Ed. Krenkel, Keramische Verbundwerkstoffe, (2002), ISBN 3-527-30529-7, pp. 48-75

[5] R. Kochendörfer, H. Hald, W. Krenkel, Design guide lines for CMC-structures, Wiley-VCH, Ed. Krenkel, Keramische Verbundwerkstoffe, (2002), ISBN 3-527-30529-7, pp. 149-172

[6] AITM, Airbus Standard 1.0006, Issue 2, 1994, 1-8

[7] A. Fink, Ein Grenzfä̈chenmodell zur Beschreibung des mechanischen Verhaltens faserverstärkter Keramiken, Dissertation, Uni Stuttgart, 1995

[8] B. Marshall and A.G. Evans, Failure mechanisms in ceramic fiber/ceramic matrix composites, J. Am. Ceram. Soc., 68 (5) (1985), pp. 225-231

[9] F. Hild, J.M. Domergue, F.A. Leckie, A.G. Evans, Tensile and flexural ultimate strength of fibre reinforced ceramic matrix composites, Int. J. Solids Structures, 31 (7) (1994), pp. 1035-1045

[10] J. Nakayama, Direct measurement of fracture energies of brittle heterogeneous materials, J. Am. Cer. Soc., 48 (11) (1994), pp. 221-229

[11] A. Szekrényes, Overview on the experimental investigations of the fracture toughness in composite materials, HEJ - Mechanical Engineering and Transport Section, (2002), http://heja.szif.hu/MET/MET-020507-A/

[12] O. Allix, P. Ladeveze, A. Corigliano. Damage analysis of interlaminar fracture specimens, Composite Structures, 31 (1995), pp. 61-74

[13] ANSYS Inc., Release 12.1. Documentation for ANSYS (2009)

[14] R. Hill, The mathematical theory of plasticity, Oxford, Clarendon Press (1950)

[15] C.F. Shih, D. Lee, Further developments in anisotropic plasticity, Journal of Engineering Materials and Technology, 100 (1978), pp. 294-301

[16] S. Valliappan, P. Boonlauloh, I.K. Lee Non-linear analysis for anisotropic materials, International Journal for Numerical Methods in Engineering, 10 (3) (1976), pp. 597-606

[17] J.R. Rice, A path independent integral and the approximate analysis of strain concentration by notches and cracks, Journal of Applied Mechanics, 35 (1968), pp. 379-386

[18] A.A. Griffith, The phenomena of rupture and flow in solids, Philosophical Transaction of the Royal Society, London, Series A, 221 (1921)

[19] D. Dugdale, Yielding of steel sheets containing slits, Journal of the mechanics and Physics of Solids, 8 (1960)

[20] G.I. Barenblatt, Mathematical theory of equilibrium cracks in brittle fracture, Advances in Applied Mechanics, Academic Press, 7 (1962)

[21] W. Krenkel, Ceramic light weight breaks, Wiley-VCH, Ed. Krenkel, Keramische Verbundwerkstoffe, (2002), ISBN 3-527-30529-7, pp. 242-267

[22] H. Tada, P.C. Paris, G.R. Irwin, The stress analysis of cracks handbook, 3rd Ed, ASME Press, 2000, pp. 58 